\title{
High Pressure High Temperature Cell for Electrical Conductivity Measurements of Earth-Type Materials
}

\author{
Christopher P. Stroemich, Member, IEEE, Edmund Sumbar, Member, IEEE,
} Fred E. Vermeulen, Member, IEEE, and F. S. Chute, Member, IEEE

\begin{abstract}
A high pressure, high temperature cell has been constructed and used to determine the temperature dependence of the electrical conductivity of various geological materials at a frequency of $60 \mathrm{~Hz}$. Test conditions in the cell approximate an in situ environment by means of a variable uniaxial confining pressure and a separately variable pore pressure. A wide array of constituents of typical oil bearing formations have been examined at temperatures up to $240^{\circ} \mathrm{C}$.
\end{abstract}

\section{INTRODUCTION}

$\mathbf{N}$ early half of the world's heavy petroleum resources are located in northern Alberta, Canada. Most of these heavy bitumens permeate sand layers deep beneath the ground surface forming what are commonly known as the oil sands. At typical formation temperatures, bitumens are very viscous, almost solid, and their separation from sand grains is difficult. The recovery of heavy oils from these subterranean reservoirs can be achieved only when the viscosity of hydrocarbons saturating the formation is reduced to a level such that they are rendered mobile under practically achievable pressure differentials, which can be accomplished by increasing formation temperatures. Several techniques to heat the underground bitumen reservoirs, such as injection of steam and hot water, or fire flooding, have been proposed and are currently under examination [1]. Studies have shown that the efficiencies of these techniques can be improved significantly by employing an electric current to preheat the oil bearing zone through ohmic or dielectric losses [2]-[5]. The general availability and the comparatively low cost of $60 \mathrm{~Hz}$ electrical energy make it the prime candidate for use during the first stages of bitumen extraction. Experiments have been performed on scaled physical models and computer simulations have been conducted to determine the best conditions for the electric preheat recovery phase [2]-[5]. The accuracy of both the physical and computer models depends on knowing the behavior of the electrical conductivities of the reservoir materials as a function of temperature. In situ techniques [6]-[11] are not well suited for making controlled measurements at elevated temperatures. To obtain conductivity values over the range of temperatures encountered during in situ electrical heating, measurements must be performed under laboratory conditions on representative samples.

Manuscript received April 12, 1991; revised December 15, 1991. This work was supported by the Alberta Oil Sands Technology and Research Authority and by the Natural Sciences and Engineering Research Council.

The authors are with the Department of Electrical Engineering, University

of Alberta, Edmonton, Alberta, Canada T6G 2G7.

IEEE Log Number 9201080.
Development of techniques suitable for earth-type materials has been of ongoing interest for many years [12]-[16]. The authors have previously reported the development of several measurement cells for determining the electrical conductivity of oil sands at temperatures up to $100^{\circ} \mathrm{C}$ [12], [13]. As well, the authors have made measurements up to $240^{\circ} \mathrm{C}$ with a pressurized capacitor-like sample holder [15]. This apparatus relied on a statically applied confining pressure to maintain sample-electrode contact, which in many cases resulted in impedance irregularities which could not be resolved by the two terminal measuring techniques employed [12]. Moreover, the system was not suitable for making measurements on cored samples.

In this paper a four-terminal apparatus [7] is described which permits the determination of the electrical conductivity of reservoir materials at power frequencies, as a function of temperature and under approximately in situ conditions, and is especially suited for making measurements on the unconsolidated oil sand and soft shales that characterize much of the hydrocarbon deposits in Alberta in Western Canada. Measurement results for the major geological strata of typical heavy oil bearing formations are then given.

\section{APPARATUS CHARACTERIZATION}

\section{A. General Concepts}

The electrical conductivity can be determined by measuring a voltage drop, $V_{s}$, across a sample whose geometrical dimensions are known, and which carries a known current, $I_{s}$. This so-called two-electrode method, illustrated in Fig. 1(a), suffers from a systematic error due to the contact resistance at the electrode/sample interface. The sample voltage is therefore overestimated, resulting in an experimentally determined conductivity whose value is lower than the true value. To overcome this problem the modified apparatus of Fig. 1(b) may be used. The two voltage probes $P_{1}$ and $P_{2}$ of this four-electrode method draw negligible current. Thus, while the contact resistance at these two probes may be quite large, it is now immaterial and does not affect the accurate determination of the true inter-probe voltage, $\Delta V$. The twoelectrode conductivity, $\sigma_{2}$, and the four-electrode conductivity, $\sigma_{4}$, are computed from the following formulae:

$$
\sigma_{2}=\frac{L \cdot I_{s}}{A \cdot V_{s}}
$$




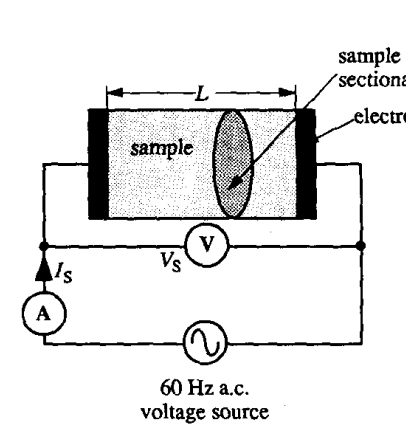

(a)

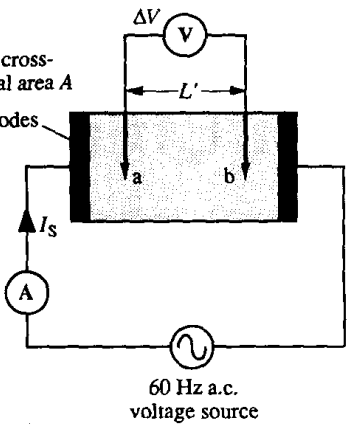

(b)

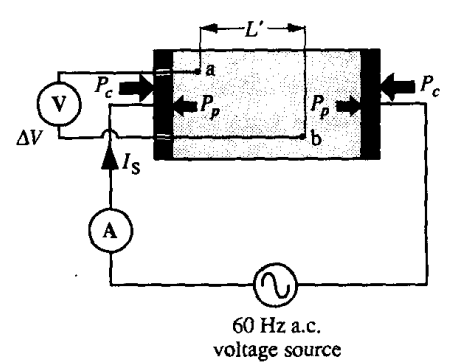

(c)

Fig. 1. Experimental concept for measuring the electrical conductivity of cylindrical samples between two electrodes. (a) Two-electrode method. (b) Four-electrode method. (c) Conceptual model of measurement cell.

$$
\sigma_{4}=\frac{L^{\prime} \cdot I_{s}}{A \cdot \Delta V_{s}}
$$

where the meanings of $L, L^{\prime}$, and $A$ are indicated in Fig. 1 .

\section{B. Apparatus}

A practical realization of the simple measurement system depicted in Fig. 1(b) for conditions of temperature and pressure approaching those encountered in situ requires a rather elaborate measurement cell. Firstly, provisions must be incorporated to recompact the samples to near in situ densities, which can be accomplished by applying a uniaxial pressure, $P_{c}$, to the ends of the sample as suggested in Fig. 1(c). In the apparatus to be described below, this pressure is provided by allowing one of the end electrodes to move as a piston under the influence of an externally applied gas pressure. With this approach the authors have been able to apply sufficient pressure to recompact the samples to the point where resistivity essentially becomes independent of pressure. An additional advantage of this approach is that as the sample expands under heating, the piston can move to accommodate the increased sample size without damage to the cell.

Secondly, in order to prevent the evaporation of moisture in the samples at elevated temperatures, means must be provided to pressurize the pore space $\left(P_{p}\right.$ in Fig. 1(c)). In the case of soft shale samples the confining pressure, $P_{\mathrm{c}}$, may suffice to prevent evaporation, provided $P_{\mathrm{c}}$ is greater than the saturated steam pressure at the highest temperature at which measurements will be conducted. However, in the case of rigid samples or unconsolidated oil sand samples, where grain to grain contact has been established by the confining pressure $P_{c}$, the pressure in the pore space must be maintained independently above the appropriate saturated steam pressure. In all measurements a net confining pressure $\left(P_{c}-P_{p}\right)$ was maintained in order to ensure positive contact between the sample and the end electrodes. The cell must provide probes for measuring the potential difference $\Delta V$ and for monitoring the sample temperatures. The authors have found that the only practical way to insert potential probes was through one of the end electrodes, as suggested in Fig. 1(c). To minimize the number of high temperature-pressure feedthroughs into the pressurized cell, these voltage probes were designed to double as thermocouples, thereby providing cell temperatures at points $a$ and $b$. With this basic design approach the authors feel that the complex changes that occur during heating in the porosity, density, and saturation levels within the cell will approximate those changes that occur naturally in a heated formation when $P_{c}$ and $P_{p}$ are chosen initially to represent the in situ overburden and pore pressures prior to heating. Thus, while the cell was not specifically designed to determine the precise nature of these complex changes, the measured electrical conductivity will substantially represent the conductivity of the sample material under conditions of in situ heating. The final implementation of the cell shown in Fig. 1(c) is illustrated in cross-section in Fig. 2, and will be referred to as the HPHT cell (High Pressure High Temperature cell).

All steel components are made of type 316 stainless steel, and all O-rings are made of Viton ${ }^{\mathrm{TM}}$. The sample $(\# 8)$ is radially confined by a Teflon ${ }^{\mathrm{TM}}$ liner $(\# 7)$ and the stainless steel walls of the cell (\#9). One end of the sample butts against a copper electrode (\#22) which is hard-soldered to the fixed stainless steel plug (\#6). This end of the sample is electrically grounded. The opposite end of the sample is energized through another copper electrode (\#22) that is hard-soldered to the movable stainless steel plug (\#10). These two electrodes (\#22) are the current carrying electrodes of the four electrode system shown in Fig. 1(c). The movable plug (\#10) is mechanically coupled with the movable stainless steel piston (\#12) by means of a brass connecting rod (\#20). The rod is electrically isolated from the piston by two Vespel ${ }^{\text {TM }}$ spacers (\#18), one of which is compressed against two O-ring face seals, making the piston able to pneumatically insulate the pore pressure, $P_{p}$, from the confining pressure, $P_{c}$. The piston unit can move along the axis of the cell as it seals on the Teflon ${ }^{\mathrm{TM}}$ liner (\#7) and adjacent stainless steel liner (\#11). The electrode-to-Teflon ${ }^{\mathrm{TM}}$ seals, one on the fixed plug and two on the piston unit, prevent water seepage past the electrodes, precluding the possibility of a shunt between the energized electrode and ground.

Two thermocouple probes (\#23) penetrate the sample to different depths from the fixed-plug end. Each probe consists of an inner core of iron/constantan thermocouple wire housed in a $1.6 \mathrm{~mm}(1 / 16-i n)$ diameter brass tube which, in turn, is isolated from the sample by a thin Teflon ${ }^{\mathrm{TM}}$ sheath. The left end of each tube has a brass mounting flange soldered to it while, at the right end, a thermocouple junction is hardsoldered to the tip, sealing the tube at that point. Both probes are rigidly installed in the thermocouple flange (\#4) which, 


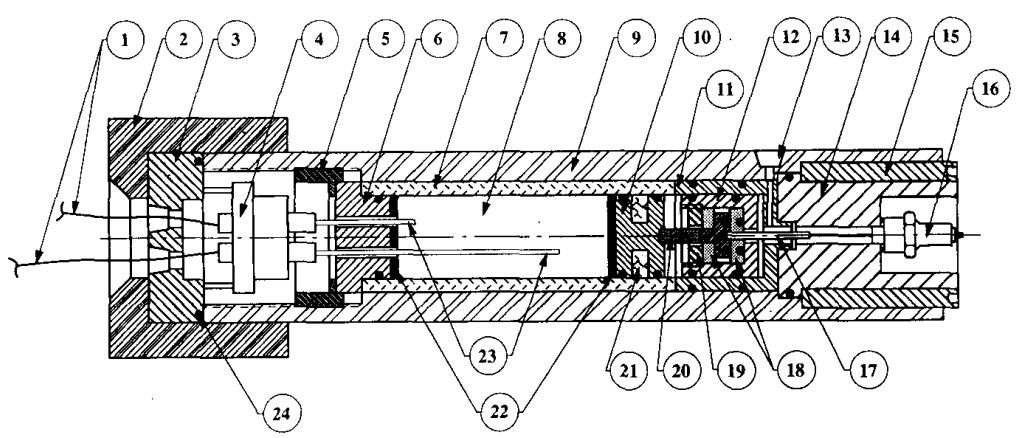

Fig. 2. Longitudinal section of HPHT cell. 1-thermocouple wires; 2-large brass nut; 3-stainless steel pore pressure flange; 4-thermocouple flange with probes; 5-bronze retaining screw; 6-fixed stainless steel plug; 7-Teflon ${ }^{\mathrm{TM}}$ liner; 8-sample under test; 9-stainless steel main cell; 10-movable stainless steel plug; 11-stainless steel liner; 12-movable stainless steel piston; 13-overburden pressure port; 14-stainless steel spark plug flange; 15-bronze retaining screw; 16-spark plug; 17-beryllium copper sliding contact; 18 -Vespel ${ }^{\mathrm{TM}}$ spacers; 19-fastener for brass connecting rod; 20-brass connecting rod; 21 -water absorbing material (fiberglass); 22-copper electrodes; 23-thermocouple probes; 24-Viton ${ }^{\mathrm{TM}} \mathrm{O}$-rings.

in turn, is attached to the pore pressure flange $(\# 3)$. The thermocouple flange (\#4) consists of several stainless steel, brass and Teflon ${ }^{\mathrm{TM}}$ components, which are not shown in Fig. 2. In addition to sensing sample temperature, these probes act as the voltage probes in the four-electrode method. As such, both probes are electrically insulated from all metallic parts and from each other and are exposed to the sample only over a distance of about $1 \mathrm{~mm}$ at the tips.

The thermocouple wires (\#1) from the two probes are carried outside the cell through $4.8 \mathrm{~mm}$ (3/16-in) diameter stainless steel tubing (not shown in Fig. 2) and terminate at pressure-sealed thermocouple connectors. The thermocouple/voltage probes, the pore pressure flange, and the tubes that house the thermocouple wire form a single unit.

Pressure $P_{c}$ is applied to the sample by the mechanical force of the piston unit which is activated by high pressure nitrogen gas which enters through a pressure port (\#13). This pressure is maintained at a constant level over the entire range of operating temperatures by the action of a pressure regulator and gas leak. Pore pressure, $P_{p}$, is applied by surrounding the Teflon ${ }^{\mathrm{TM}}$ liner (\#7) and sample (\#8) with high pressure nitrogen gas which is introduced through another port (not shown in Fig. 2) at the fixed-plug-end of the apparatus. Pore pressure gas enters the sample directly through the thermocouple/voltage probe holes. The nitrogen gas also migrates along milled passages on the outside of the Teflon ${ }^{\mathrm{TM}}$ liner into the space behind the movable stainless steel plug to establish a zero pressure differential across it. Unlike the confining pressure circuit, the pore pressure line is fixed in volume so that pore pressure will fluctuate with temperature. Both confining and pore pressure systems are plumbed with stainless steel tubing from a single source of gas.

During an experiment the HPHT cell is placed in a conventional oven where sample temperature can be controlled. The two gas lines are fed through one of the oven walls, as is the electrical connection to the sample. Electric current reaches the sample from outside the cell via a spark plug (\#16) which acts as a high pressure, high temperature electrical feedthrough device (and also provides the confining-pressure gas leak). The spark plug electrode engages a sliding contact (\#17) on the piston unit which, in turn, is in contact with one end of the sample. The electric circuit is completed by returning current from the sample to the steel body of the cell.

\section{MEASUREMENTS}

\section{A. Test Conditions}

The cell with an installed specimen was pressurized by confining and pore pressures of $5600 \mathrm{kPa}$ and $2000 \mathrm{kPa}$, respectively, at least 12 hours before a test to allow the sample structure to accommodate the new stresses. During an experiment, the confining pressure remained at its initial level. The pore pressure was permitted to change with increasing temperature, thus approximating the natural increases in in situ pressure that would inevitably occur in a heated formation. The sample temperature was increased from room temperature at $20^{\circ} \mathrm{C}$ in 12 steps up to $240^{\circ} \mathrm{C}$. Conductivity measurements were performed at each of these steps, once the temperature distribution in the sample was approximately uniform.

Electric signals from the cell were monitored by an HP 3825 Automatic Data Acquisition System. An HP 82300B HP BASIC Language Processor controlled the entire experiment by continuously sensing sample temperatures, performing current and voltage measurements at appropriate temperature conditions, computing conductivities and checking for possible loss of integrity of the HPHT cell, printing and displaying intermediate results, and changing oven temperatures. At the end of an experiment, a curve-fitting routine was applied to the collected sample conductivity data to find a third degree polynomial to approximate the measured points. Both the polynomial and the data points were then plotted.

Only four-electrode results were used to prepare the final data shown in this paper. However, since the four-electrode voltage was measured across only a section of the sample, the natural inhomogeneity of tested materials could produce erroneous results, particularly when the voltage electrodes were placed in a region of locally higher conductivity. In order to detect this condition, four-electrode conductivity measurements were always compared to two-electrode conductivity measurements. An exceptionally high discrepancy 
TABLE I

Summary of SAmple Characteristics

\begin{tabular}{|c|c|c|c|c|}
\hline Material & $\begin{array}{l}\text { Density } \\
{\left[\mathrm{g} \cdot \mathrm{cm}^{-3}\right]}\end{array}$ & $\begin{array}{c}\text { Water } \\
\text { Content } \\
\text { [weight \%] }\end{array}$ & $\begin{array}{l}\text { Oil Content } \\
\text { [weight \%] }\end{array}$ & Sample Description \\
\hline Amoco Shale & 2.03 to 2.24 & 10.3 to 14.0 & - & $\begin{array}{l}\text { soft, non homogeneous, greyish, } \\
\text { stratified structure }\end{array}$ \\
\hline $\begin{array}{l}\text { Amoco Shale \& Oil } \\
\text { Sand }\end{array}$ & 2.04 to 2.17 & 8.5 to 10.6 & 2.3 to 3.6 & $\begin{array}{l}\text { soft, non homogeneous mixture } \\
\text { of oil sand and shale }\end{array}$ \\
\hline Syncrude Shale & 2.09 to 2.31 & 9.2 to 17.5 & - & $\begin{array}{l}\text { relatively soft and uniform cores, } \\
\text { dark grey-blackish in color }\end{array}$ \\
\hline UTF Shale & 2.08 to 2.22 & 13.8 to 18.1 & - & $\begin{array}{l}\text { grey, non uniform structures of } \\
\text { hard material interspersed with } \\
\text { softer clay-like lenses }\end{array}$ \\
\hline Syncrude Lim & 2.57 to 2.63 & $\overline{1.1 \text { to }} \overline{2.3}$ & - & $\begin{array}{l}\text { very hard, whitish, uniform } \\
\text { cores }\end{array}$ \\
\hline Mined Lean Oil Sand & 2.09 to 2.21 & 7.2 to 8.8 & 6.6 to 8.0 & $\begin{array}{l}\text { uniform blackish mixture of sand } \\
\text { and oil }\end{array}$ \\
\hline Mined Rich Oil Sand & 1.93 to 2.03 & 1.5 to 2.6 & $11 . \overline{7}$ to 13.6 & $\begin{array}{l}\text { uniform blackish mixture of sand } \\
\text { and oil }\end{array}$ \\
\hline UTF Oil Sand & 1.89 to 2.01 & 1.9 to 3.8 & $12 . \overline{1}$ to $14 . \overline{4}$ & $\begin{array}{l}\text { frozen cores with uniform sand } \\
\text { grain matrix }\end{array}$ \\
\hline Silica Sand \& Brine & 1.97 to 2.11 & 11.1 to 14.1 & - & $\begin{array}{l}\text { cle en silica sand saturated with } \\
5000 \mathrm{mg} / \mathrm{L} \mathrm{NaCl} \text { brine }\end{array}$ \\
\hline
\end{tabular}

between the two values of conductivities thus obtained could be an indication that the sample was most likely highly inhomogeneous and that the test results should be discounted.

\section{B. Sample Preparation}

All geological samples described in this paper originate from the Athabasca Oil Sands deposit, located near Fort McMurray in northeastern Alberta, Canada. They were supplied by Syncrude Canada Ltd., Amoco/AOSTRA ${ }^{1} /$ GLISP $^{2}$ and the AOSTRA UTF ${ }^{3}$ project. After extraction from the borehole, all cored samples were immediately sealed in PVC pipes. Unconsolidated oil sands provided by the Alberta Research Council's sample bank were obtained from mined oil sand in sealed pails. Both the cored and the unconsolidated samples were stored in temperature and humidity-controlled conditions at about $8^{\circ} \mathrm{C}$ until conductivity tests could be performed. The UTF oil sand samples were frozen at temperatures of about $-20^{\circ} \mathrm{C}$ after their extraction and were stored in this condition prior to conductivity tests. Some typical geophysical properties of the samples are listed in Table I.

Before installation in the HPHT cell, all samples were shaped into cylinders $38 \mathrm{~mm}$ in diameter and between 92 and $108 \mathrm{~mm}$.long. The Syncrude shales, as a relatively soft material, were formed and sized to the required dimensions in a simple trimming device and then inserted into the Teflon ${ }^{\mathrm{TM}}$ liner. The unconsolidated oil sands, as well as the Amoco oil sands and shales, were directly compacted in the Teflon ${ }^{\mathrm{TM}}$ liner. The frozen UTF oil sands were machined to the required dimensions and, still frozen, installed in the Teflon ${ }^{\mathrm{TM}}$ liner. This procedure was used to minimize damage to the internal structure of the sample. The UTF shales and the Syncrude limestones were very hard and fragile and required careful machining or coring before their installation in the sample holder. Two 4.8-mm (3/16-in) holes were subsequently drilled into the ground-end of the various samples to accommodate the thermocouple/voltage probes. The Teflon ${ }^{\mathrm{TM}}$ liner with the sample was then installed in the HPHT cell which was sealed and pressurized.

\footnotetext{
${ }^{1}$ Alberta Oil Sands Technology and Research Authority

${ }^{2}$ Gregoire Lake In Situ Steam Pilot

${ }^{3}$ Underground Test Facility
}

TABLE II

SUMmary of MEASUREd Electrical

Parameters of Tested Geological Samples

\begin{tabular}{|c|c|c|c|c|c|}
\hline material & $\begin{array}{l}\begin{array}{l}\text { number of } \\
\text { semples that } \\
\text { contributed } \\
\text { dasta }\end{array} \\
\end{array}$ & $\begin{array}{c}\sigma_{24} \\
{\left[\mathrm{~S} \cdot \mathrm{m}^{-1}\right]}\end{array}$ & $\begin{array}{c}b \\
{\left[K^{-1}\right]}\end{array}$ & $\begin{array}{c}c \\
{\left[\mathrm{~K}^{-2}\right]}\end{array}$ & $\begin{array}{c}d \\
{\left[\mathrm{~K}^{-3}\right]}\end{array}$ \\
\hline Amoco Shale & 4 & $260 \cdot 10^{-3}$ & $2.49 \cdot 10^{-2}$ & $1.07 \cdot 10^{-4}$ & $-6 . \overline{10} \cdot 10^{-7}$ \\
\hline Amoco Shale \& Oil Sand & 3 & $223 \cdot 10^{-3}$ & $2.30 \cdot 10^{-2}$ & $6.43 \cdot 10^{-5}$ & $-4.60 \cdot 10^{-7}$ \\
\hline Syncrude Shale & 6 & N/A & $2.99 \cdot 10^{-2}$ & $\overline{6.94 \cdot 10^{-5}}$ & $-6.01 \cdot 10^{-7}$ \\
\hline UTF Shale & 4 & $2 \overline{77} \cdot 10^{-3}$ & $3.65 \cdot 10^{-2}$ & $-1.16 \cdot 10^{-6}$ & $-3.43 \cdot 10^{-7}$ \\
\hline Syncrude Limestone & 4 & $37 \cdot 10^{-3}$ & $2.21 \cdot 10^{-2}$ & $1.11 \cdot 10^{-4}$ & $-4.42 \cdot 10^{-7}$ \\
\hline Mined Lear Oil Sand & 11 & $\overline{73 \cdot 10^{-3}}$ & $2.77 \cdot 10^{-2}$ & $\overline{6.85 \cdot 10^{-6}}$ & $-2.72 \cdot 10^{-7}$ \\
\hline Mined Rich Oil Sand & 8 & $1.7 \cdot 10^{-3}$ & $2.75 \cdot 10^{-2}$ & $1.45 \cdot 10^{-4}$ & $-8.84 \cdot 10^{-7}$ \\
\hline UTF Oil Sand & 5 & $5 . \overline{4 \cdot 10^{-3}}$ & $\overline{1.35} \cdot \overline{10^{-2}}$ & $2.32 \cdot 10^{-4}$ & $-1 . \overline{13} \cdot 10^{-6}$ \\
\hline Silica Sand and Brine* & 5 & $179 \cdot 10^{-3}$ & $2.50 \cdot 10^{-2}$ & $1.13 \cdot 10^{-3}$ & $-1.68 \cdot 10^{-7}$ \\
\hline
\end{tabular}

"Sample prepared in laboratory: clean silica sand saturated with $5000 \mathrm{mg} / \mathrm{L} \mathrm{NaCl}$ brine

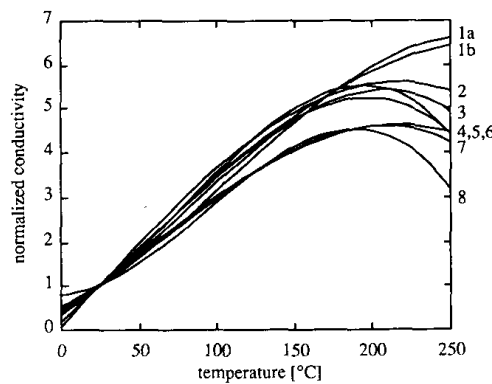

Fig. 3. Normalized conductivity vs. temperature functions obtained for tested geological materials. 1a-Syncrude limestone; $1 \mathrm{~b}-7000 \mathrm{mg} / \mathrm{L} \mathrm{NaCl}$ brine; 2-UTF Shale; 3-Amoco Shale; 4-Mined Rich Oil Sand; 5-Syncrude Shale; 6-Mined Lean Oil Sand; 7-Amoco Shale and Oil Sand; 8-UTF Oil Sand.

\section{Results}

During each of the HPHT tests, 12 conductivity measurements were taken at temperatures from about $20^{\circ} \mathrm{C}$ (room temperature) to $240^{\circ} \mathrm{C}$. The 12 data points were approximated by a third degree polynomial, using the least squares technique:

$$
\frac{\sigma(t)}{\sigma_{24}}=1+b \cdot(t-24)+c \cdot(t-24)^{2}+d \cdot(t-24)^{3}
$$

where $\sigma_{24}$ is the sample conductivity at $24^{\circ} \mathrm{C}, b, c$, and $d$ are the normalized polynomial coefficients, and $\sigma(t)$ is the conductivity at temperature $t$. Note, that the above equation represents the electrical conductivity normalized with respect to $\sigma_{24}$. Table II summarizes electrical parameters that have been obtained for different materials during the current measurement program and Fig. 3 displays the corresponding conductivity functions. Each curve displayed is based on an average of multiple sample measurements.

\section{Discussion of Results}

Fig. 3 indicates that the majority of the conductivity functions can be characterized by a substantially linear increase with temperature at lower temperatures and by a decline at higher temperatures. The data suggests that the following two factors have the dominant influence on the the shape of the 


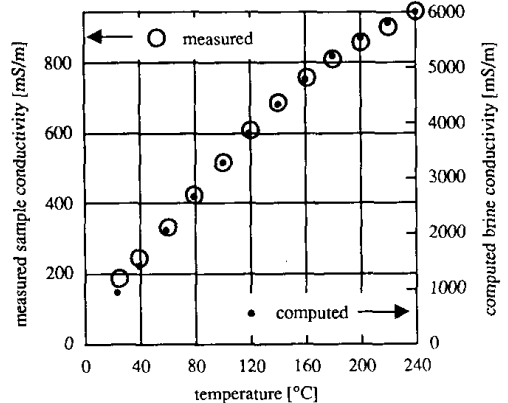

Fig. 4. The measured conductivity of a $100 \%$ brine $(0.086 \mathrm{~mol})$ saturated clean sand sample and the computed conductivity of a $0.086 \mathrm{~mol}$ brine solution.

polynomials:

-ion concentrations in the connate water of the samples,

- content and type of clays present in the samples.

For example, consider the change in the electrical conductivity with temperature of the connate water itself, which contains mainly dissolved sodium chloride at concentrations ranging from $1000-10000 \mathrm{mg} / \mathrm{L}$ for typical formation materials [17]. The behavior of the electrical conductivity of such geothermal brines has been studied extensively [18], [19]. Initially, as the temperature is increased the viscosity of the brine decreases, resulting in an increase in the mobility of the ions in solution and a nearly linear increase in the conductivity. As the temperature continues to increase the density in the pore water is reduced, resulting in a lowering of the dielectric constant. In turn, this leads to an increased association between ion pairs and a tendency to decrease the conductivity of the brine, thereby at least partially offsetting the increase in conductivity related to the decrease in brine viscosity.

The increase in the electrical conductivity with temperature of actual geological samples must in part be due to the effects described above. Consider a hypothetical sample consisting of clean silica sand compacted to achieve grain to grain contact and $100 \%$ saturated with a brine solution. In this case (provided the confining pressure is enough to ensure that porosity changes with temperature are negligible) Archie's law [20] suggests that the variation in electrical conductivity with temperature for such a sample will be identical to that of the brine itself.

Such a sample was prepared, using clean silica sand $100 \%$ saturated with a $5000 \mathrm{mg} / \mathrm{L}(0.086 \mathrm{~mol}) \mathrm{NaCl}$ aqueous solution. Measurements of the electrical conductivity were made over the range $24^{\circ} \mathrm{C}$ to $240^{\circ} \mathrm{C}$, and the results are shown in Fig. 4. Also shown in Fig. 4 is the temperature response of the brine solution itself as calculated from the data provided by Ucok et al. [19]. Although the two responses are drawn to different vertical scales, their congruence indicates that the increase in conductivity of the brine-sand sample depends solely on the ion concentration in the brine. Further, this agreement verifies that the measurement cell is capable of accurate measurements of the temperature response of geological samples over the temperature and pressure range of interest.
Of all the reservoir materials that have been tested in the HPHT cell, only the Syncrude limestone (curve \#1a in Fig. 3) exhibited a conductivity whose variation with temperature could be explained by only considering ion concentrations. Indeed, using the data of Ucok et al. [19], it has been shown that the calculated conductivity of $7000 \mathrm{mg} / \mathrm{L}(0.12$ mol) aqueous solution of sodium chloride (curve \#1b) almost exactly matches the limestone characteristic. For the limestone samples, then, it is inferred that the brine ionic conduction is the predominant factor determining their electrical conductivity. Indeed, examination of Fig. 3 for the response of the electrical conductivity below about $180^{\circ} \mathrm{C}$ indicates that the dominant conduction mechanism in all samples is governed by the ions in solution.

Since the variation of the conductivity with temperature of the remaining samples tested in the HPHT cell did not follow the brine-sand response, it may be concluded that their conductivities cannot be explained solely in terms of the ionic conductivity of the pore water. A common feature of these materials is the presence of clays in their structures. Clay particles have an excess of positive ions (so called counterions) adhered to their surfaces. In an aqueous environment, the counterions acquire some mobility and increase the overall conductivity of a mineral. In general, this conductivity increases faster with temperature than that of clay-free samples [21], [22]. At high enough temperatures, complex chemical reactions may transform the molecular structure of clays and the electrical conductivity of clay-electrolyte compounds may be reduced. These temperatures can be as low as or below $200^{\circ} \mathrm{C}$ [23].

Detailed compositional analysis on the samples was not undertaken and it was therefore not possible to quantitatively discuss the relative influence of the clays on the increase in electrical conductivity with temperature. However, such a quantification was not the objective of the measurement program. Rather, the intent was to provide a functional relationship between conductivity and temperature that would be useful in the computer simulation of electrothermal processes.

\section{CONCLUSIONS}

A high pressure, high temperature cell used for measurements of the $60-\mathrm{Hz}$ electrical conductivity of earth-type materials as a function of temperature and under approximately in situ conditions has been described. The performance of the apparatus was verified by testing many samples consisting of pure silica sand fully saturated with brine. Additional calibrating tests and their evaluation, as well as the metrological analysis of the measuring system showed that the results obtained with the HPHT cell were repeatable and accurate to within $\pm 10 \%$.

The variation of electrical conductivity with temperature for the main geological components of an oil bearing formation have been extensively studied. The electrical conductivity of all tested materials increased linearly with temperature, up to about $150-200^{\circ} \mathrm{C}$. The ionic conductance of interstitial brines and the counterion conductance of clays are believed to be the main factors contributing to the conductivity growth in this region. Beyond the linear part, the conductivity rise 
was slower, and all but one sample (limestone) exhibited a conductivity drop at temperatures above $200^{\circ} \mathrm{C}$. Insufficient data has been collected at these elevated temperatures to permit the development of a conductivity model at these elevated temperatures and future measurement programs should address this issue.

The family of normalized conductivity characteristics shown in Fig. 3 and described in Table II can be used in predicting the in situ temperature behavior of electrically heated oil sands and the adjacent strata. These functions are being applied by the authors in numerical simulators to model heating patterns for different electromagnetic oil recovery systems [24].

\section{ACKNOWLEDGMENT}

Thanks are also due to Jim Fearn for his technical advice and help. Finally, the Machine Shop staff of the Electrical Engineering Department should be thanked for the many hours spent building the measurement cell components.

\section{REFERENCES}

[1] AOSTRA Technical Handbook on Oil Sands, Bitumens and Heavy Oils, Alberta Oil Sands Technology and Research Authority (AOSTRA, 500 Highfield Place, 10010-106 Street, Edmonton, Alberta, Canada, T5J 3L8) Technical Publication Series \#6, (1989)

[2] F. E. Vermeulen; F. S. Chute, and M. R. Cervenan, "Physical modeling of the electromagnetic heating of oil sand and other earth-type and biological materials," Can. Elec. Eng. J., vol. 4, no. 4, pp. 19-28, 1979.

[3] F. E. Vermeulen and F. S. Chute, "Electromagnetic techniques in the in-situ recovery of heavy oils," $J$. of Microwave Power, vol. 18 , no. 1 , pp. 15-29, 1983.

[4] R. G. McPherson, F. S. Chute, and F. E. Vermeulen, "Recovery of Athabasca bitumen with the electromagnetic flood (EMF) process," $J$ Canadian Pet. Tech., Jan.-Feb., pp. 44-51, 1985.

[5] F. S. Chute and F. E. Vermeulen, "A study of the technical and economical feasibility of an electric preheat process for in situ recovery from Athabasca Oil Sands," AOSTRA J. Res., vol. 3, pp. 139-154, 1987.

[6] L. J. Briggs, "Electrical instruments for determining the moisture temperature, and soluble salt content of soils," U. S. Dept. Agr. Bul. $15,1899$.

[7] N. E. Edlefsen and Alfred B. C. Anderson, "The four-electrode resistance method for measuring soil-moisture content under field conditions," Soil Sci., vol. 51, pp. 367-376, 1941.

[8] J. D. Rhoades and J. van Schilfgaarde, "An electrical conductivity probe for determining soil salinity," Soil Sci. Soc. Am.J., vol. 40, pp. 647-650, 1976.

[9] R. S. Austin and J. D. Rhoades, "A compact, low-cost circuitry for reading four-electrode salinity sensors," Soil Sci. Soc. Am. J., vol. 43, pp. $808-810,1979$.

[10] 3. D. Rhoades and D. L. Corwin, "Determining soil electrical conductivity-depth relations using an inductive electromagnetic soil conductivity meter," Soil Sci. Soc. Am. J., vol 45, pp. 255-260, 1981.

[11] C. Gatlin, Petroleum Engineering, Drilling and Well Completions. Englewood Cliffs, NJ: Prentice-Hall Inc., 1960.

[12] F. S. Chute, F. E. Vermeulen, M. R. Cervenan, and F. J. McVea "Electrical properties of Athabasca oil sands," Can. J. Earth Sci., vol. 16, no. 10, pp. 2009-2021, 1979.

[13] F. S. Chute, M. R. Cervenan, and F. E. Vermeulen, "Simple cell for the measurement of the radio-frequency electrical properties of earth materials," Rev. Sci. Instrum., vol. 49, pp. 1675-1679, 1978.

[14] R. L. Jesch and R. H. McLaughlin, "Dielectric measurements of oil shale as functions of temperature and frequency," IEEE Trans. Geosci. Remote Sensing, vol. GE-22, pp. 99-105, Mar. 1984.

[15] A. D. Hiebert, "Numerical simulation of the electric pre-heat and steam drive bitumen recovery process for the Athabasca Oil Sands," Ph.D. thesis, Department of Electrical Engineering, University of Alberta, Edmonton, 1986

[16] F. E. Vermeulen, F. S. Chute, and E. Sumbar, "Electrical conductivity of Clearwater shale and rich oil sand as measured in the laboratory," Final Report for AOSTRA Agreement no. 296 A, Applied Electromagnetics
Laboratory, Department of Electrical Engineering, University of Alberta, Edmonton, June 1987.

[17] D. A. Hackbarth and N. Nastasa, "The hydrogeology of the Athabasca Oil Sands area, Alberta," Bulletin 38, Alberta Research Council, 1979.

[18] A. S. Quist and W. L. Marshall, "Electrical conductances of aqueous sodium chloride solutions from 0 to $800^{\circ}$ and at pressures to 4000 Bars," J. Phys. Chem, vol. 72, no. 2, pp. 684-703, Feb. 1968

[19] H. Ucok, I. Ershaghi, and G. R. Olhoeft, "Electrical resistivity of geothermal brines," J. Pet. Tech., pp. 717-727, Apr. 1980.

[20] G. E. Archie, "Electrical resistivity log as an aid in determining some reservoir characteristics," Trans. AIME, vol. 146, no. 54, 1942.

[21] C. Clavier, G. Coates, and J. Dumanoir, "Theoretical and experimental bases for the dual-water model for interpretation of shaly sands," Soc. Pet. Eng. J., pp. 153-168, Apr. 1984.

[22] M. H. Waxman and E. C. Thomas, "Electrical conductivities in shaly sands- $\mathrm{L}$. The relation between hydrocarbon saturation and resistivity index; II. The temperature coefficient of electrical conductivity," J. Pet. Tech., Feb. 1974, pp. 213-223; Trans. AIME, 257.

[23] W. D. Gunter and G. W. Bird, "Inorganic geochemistry," in AOSTRA Technical Handbook on Oil Sands, Bitumens and Heavy Oils (AOSTRA Technical Publication Series \#6), 1989.

[24] F. S. Chute, F. E. Vermeulen, E. Sumbar, C. P. Stroemich, and J. Fearn, "Electrical heating of oil sand reservoirs," Final Rep. for AOSTRA Agreement no. 630, Applied Electromagnetics Laboratory, Department of Electrical Engineering, University of Alberta, Edmonton, Jan. 1991

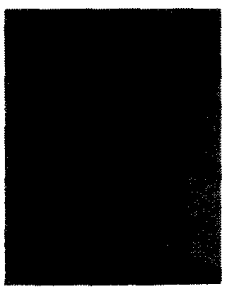

Christopher P. Stroemich (M'87) was born in Poland. He received the M. Eng. and Ph.D. degrees in electrical engineering from the Wroclaw Technical University, Poland.

He has held academic positions in Poland, $\mathrm{Al}$ geria, and Canada. His research interests are in measurement techniques, instrumentation, and control systems.

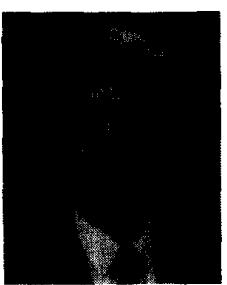

Fred E. Vermeulen (S'59-M'62-S'S'64-M'73) was born in Stuttgart, Germany. He received the B.Sc. degree from the University of Alberta, the M.A.Sc degree from the University of British Columbia, and the Ph.D. degree from the University of Alberta in 1966, all in electrical engineering.

From 1966 to 1967 he was a National Research Council Postdoctoral Fellow at the European Organization for Nuclear Research at Geneva, Switzerland, where he was engaged in the study of space charge problems as related to the transport of ion beams. In 1967 he assumed an academic position at the University of Alberta, where he is currently Professor of Electrical Engineering. His research is in applied electromagnetics, particularly the physical and numerical modeling of the electromagnetic heating of materials.

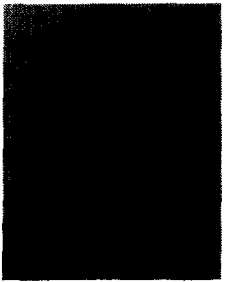

F. S. Chute (S'60-M'65) received the M.A.Sc. degree from the University of British Columbia, Vancouver, B.C., Canada, in 1964 and the Ph.D. degree from the University of Alberta, Edmonton, Alta., Canada in 1966, both in electrical engineering.

He served in the Canadian Armed Forces and was involved in the design and maintenance of radar and VHF/UHF communications systems. He began his academic career as an Assistant Professor at the Royal Military College in Kingston, Ont., Canada, and is presently a Professor in the Department of Electrical Engineering at the University of Alberta. His research work relates primarily to applied electromagnetics with a special interest in the numerical and physical modeling of electromagnetic systems designed to heat materials. 


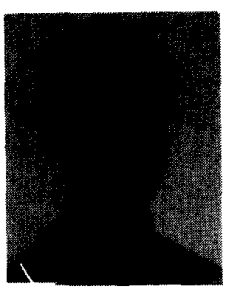

Edmund Sumbar (M'87) was born in 1954 in Calgary, Canada. He received the B.Sc. and Ph.D. degrees in electrical engineering from the University of Alberta.

His interests lie in computer applications, especially the modeling of electromagnetic phenomena. 